\title{
Molecular Carcinogenesis
}

National Cancer Institute

\section{Source}

National Cancer Institute. Molecular Carcinogenesis. NCI Thesaurus. Code C20121.

Research that focuses on the genetics and mechanisms of cell transformation; the role of oxygen radicals in the carcinogenesis process; and identification and properties of tumor promoters and mechanisms of tumor promotion. 